\title{
The Influence of Age and Gender on the Leadership Styles
}

\author{
Bhargava R. Kotur ${ }^{1}$, S. Anbazhagan ${ }^{2}$ \\ Department of Life Long Learning, Bharathidasan University, Khajamalai Campus, Trichy, TN, India.
}

\begin{abstract}
The aim of this study is to investigate the different leadership styles of the workers and the influence of age and gender on the leadership styles of the workers, in the Chittoor Sugar factory located at Chittoor, a south Indian town. The study concentrated on the three interesting leadership styles that are at the top, bottom and the middle of the leadership authority hierarchy, namely the autocratic, democratic and the laissez-faire leadership styles. The study reveals that the demographic leadership style is the dominant one and age and gender have their own influence on the worker's leadership styles. The study also reveals that with increase in age relatively lesser authority is exhibited by the workers and gender too is found to influence the leadership styles of the workers.
\end{abstract}

Keywords: Leadership styles, Autocratic, Democratic, Laissez-faire, Age, Gender

\section{Introduction}

It is a common perception that the old people fail to do certain tasks at the efficiency of the younger people. For example old persons can't run at the rate of a teenager. But at certain tasks the older people can do better than youngsters (Belal et al., 2010). For example old people can give better advices against the young ones in general.

It is again a common observation that male and female differ in their behavior in many ways. The studies (Winter et al., 2001) also say that there are certain differences in the functioning of the male and female employees.

These differences in age and gender, indeed affect the leadership behavior of the individuals as well. There are many studies on the influence of age and gender on the leadership style of the individuals (Ojode et al., 1999). With growing age people are capable of understanding their fellow men better and hence can deal with them in a more positive way. Leadership is concerned with understanding their followers better in order to accomplish the destined task. So, naturally the elder people can be better leaders than the younger ones in general. Many studies on leadership are in agreement with this statement (Mirani et al., 2003). Even due to the gender differences too, there are notable differences in the leadership behavior of the individuals (Babcock, 2008).

The aim of this study is to investigate the influence of these two factors age and gender on the leadership behavior of the employees - specifically on the workers in the Chittoor Sugar factory located at the Chittoor town of South India. Various studies (Eagly, Karau, \& Makhijani, 1995; Thompson, 2000) on leadership have investigated the influence of the leader's (boss's) - Age and Gender- on the followers' behavior and performance. But, in contrary to that the aim of this study is to investigate the influence of these two factors - Age and Gender - on the worker's own leadership styles.

\section{Related Literature}

A person who leads a group of people towards a common goal, is knows as a leader (Andrew, 2009). The leader influences his group members to accomplish the specified objectives and the way in which the leader handles his followers is known as leadership style (Sheikh, 2001). According to Adeyemi and Brlarinwa (2013) leadership is "the art or process of influencing people so that they will strive willingly towards the achievement of objects". Yukl (2004) point is that, leadership is an act of influencing subordinates to accomplish organizational goals through authority.

Different theories of leadership classify leadership in different ways. Based on the use of authority, leadership is classified into three types as autocratic, democratic and laissez faire leadership styles (Adeyemi, 2004). Maximum authority is exhibited in the autocratic leadership style and this leader always wants to command, order his followers to comply. This leader orders but will not hear to his followers (Bass, 1990). On the other hand, in democratic leadership style the leader gives equal priority to each individual under him and feels himself/herself as an important member of the organization (Adeyemi, 2007). In laissez-faire leadership style the leader leaves the subordinate free to make decision and exercise powers. The leader has least role and participation in the decisions made by his group members in the organization (Ogunsanwo, 2000). These three styles - autocratic, democratic, and laissez-faire (free-rein) - has their own merits and limitations too and none of 
these could be universally applied. Depending on the situation and the followers - the leader has to choose his leadership style in order to be effective (Bass, 1990).

Leaders and styles of leadership may vary based upon age and age groups of the leader and the follows as well. It has been stated, "With an older leader, the team may be more open to a leader's transformational behaviors, because the team members may be more accepting of the leader's special status" (Kearney, 2008). Van Vugt (2006) claims that, "age relates to leadership in a complicated way, according to the psychological literature. Some research finds a positive correlation between age and leadership, whereas others find a zero or negative correlation". In the present time, evidence for this link between age and leadership can still be found in professions that require a considerable amount of specialized knowledge and experience, such as in science, politics, and arts (Van Vugt, 2006). Cagle (1988) has regarded age as one of the factors that determine the leadership style. Apart from the professional and academic knowledge, it is commonly believed that age and experience might play important roles in leadership behaviors. In many cultures, the myth is that as people get older they become wiser due to more exposure and experience. For example in African culture, experience is considered as a function of age and therefore older peoples are given priority for leadership positions in different organizations (Ahiazu, 1989).

It is possible that males and females might lead from different perspectives. Winter, Neal and Waner (2001) claim that "Current psychological research on leadership and team interaction suggests that men and women exhibit different leadership styles and interpersonal communication styles in a variety of small-group situations from student problem- solving situations to industry and community situations". According to Lantz "women executives are much more likely than males to be a department head or to fill some other staff position, whereas men are much more likely to be a chief executive officer (CEO), chief operating officer (COO), president, or vice president" (Lantz, 2008). Babcock (2008) states that "Rather than intentional acts of bias, second-generation gender biases reflect the continuing dominance of traditionally masculine values in the workplace". According to common perception, women are more emotional and less competitive than men. For example, some authors have written that "Women are significantly more risk averse, tend to be less overconfident and behave less competitively oriented" (Beckman and Menkhoff, 2008).

The effectiveness of the leaders more or less dictated the fate of the hotels (Li, Tse, \& Xie, 2007). The hotel managers' demographic characteristics including age influenced the business success. Mirini, Narjo and Kumbhar (2003) explored the needed leadership competencies. The results showed that there were highly significant differences between the age groups and leadership competencies. In terms of age, there is a significant difference between leadership competencies and general managers' age groups, which mirrors the results found by Mirani et al., (2003). Ojode et al., (1999) claims that gender, age do influence the leader styles. A few studies included gender, age, and education as demographic variables in their examination of leadership styles. These studies produced mixed findings on the significance of the effects of these variables on leadership style. The studies of (Kazan, 2000; Payden, 1997; Thomas, 1996; Rasor, 1995) showed notable differences in leadership style due to age. Basing on the study (2004) "Age influences on the leadership styles and behavior of managers" - Titus Oshagbemi - claims that the younger and older managers, exhibit different leadership styles and older managers consulted more widely and favor more participation in comparison with younger managers. Belal et al., (2010) on their study on Afghans and Americans have concluded that - Age and Gender - indeed have their impact on the leadership styles of individuals.

Some studies (Van Engen and Willemsen, 2004)) have shown mixed empirical evidence for gender influence on the leadership styles.

Hence, it was considered very important to investigate the influence of age and gender on the leadership styles of the workers and therefore the study was conducted.

\section{Problem and Objectives}

There is no noted research on the correlation between the employee's leadership styles and the two variables - Age and Gender - especially concerning the autocratic, democratic and laissez-faire leadership styles in the Chittoor sugar factory located at the Chittoor town of south India. This study therefore aims to investigate and explore such relationship and consequently the research problem is formulated as follows.

To study the Influence of age and gender on the Leadership Style of the workers in the Chittoor Sugar factory, located at the Chittoor town of Andhra Pradesh, South India.

The broad objective of this research could be narrowed down to the duo on the sample of the study: A) To Study the different Leadership Styles of workers B) To study the Influence of the two variables - Age and Gender - on the Leadership Style of the Workers.

\section{Leadership Styles Chosen for the Study}

For the purpose of this study, only three leadership styles are chosen and these are a) Autocratic (authoritative) leadership style b) Democratic leadership style and c) Laissez-fair leadership style. 


\section{1 Reasons for choosing the above styles}

The following are the reasons in choosing only the above three leadership styles for this study. i) Autocratic, democratic and laissez-faire fall at the top, the middle and the bottom in terms of exerting authority by the leader (Bass, 1990). So, naturally it is interesting to study these three leadership styles. ii) Sociology says that the psychology of the group has impact on the members of the group (Kelman, 1958). The group members will acquire some characteristics of the group either willingly or unwillingly. In accordance with this principle, Indians should be more democratic in nature, India being a democratic country. In order to test this dictum on the workers of the firm, democratic leadership style is included in this study. iii) The other styles, notably transformational and transactional - have been extensively studied by various researchers in different studies throughout the world and hence, the other leadership styles were not considered for this study. iv) Questionnaire to test all the leadership styles is costly and is not within the affordable reach of the researcher and this too is a reason to confine the study only to the selected three leadership styles.

\section{Research Methodology}

This is mainly based on the survey conducted on the workers in the firm. Based on the data collected from the workers, the hypotheses (given later) set forth in this research were tested using suitable statistical tabulations and tests.

\subsection{Research Universe and Sample}

This research is focused on the workers in the Sugar factory at Chittoor, a south Indian town. The language of the workers is Telugu, a South Indian language. The universe of study comprises of 652 employees. Among them 36 employees hold a supervisory role and the rest of 616 are the workers.

In order to collect the data, simple random sampling technique was used in the survey. In this sampling technique, each unit in the universe has equal chance of being chosen for the study. The researcher had no criteria in selecting the participants from the Universe. The sample comprised of 127 workers out of the 616.

The questionnaire was used to collect the necessary information from the workers. In this method of data collection, cost and time could be utilized efficiently.

\subsection{The Leadership Questionnaire}

As mentioned above questionnaire was used to collect the data from the workers. The questionnaire was the courtesy of the Sage Publications and was used to determine the leadership styles and leadership potentials of the workers. It contains 18 statements in all that identify and measure the key aspects of leadership behavior. Each statement of the questionnaire relates to three styles chosen, either to autocratic or democratic or laissez-faire leadership styles. The worker has to judge how frequently the behavior described in the statement is exhibited by him/her.

The Questionnaire has a scale of 1 to 5 . The five numbers mean as follows. The choice ' 1 ' indicates Strongly Disagree, ' 2 ' indicates - Disagree, ' 3 ' indicates - Neutral, ' 4 ' indicates - Agree and ' 5 ' indicates Strongly agree. The leadership questionnaire had to be completed by the worker. On the questionnaire, the worker has to answer the questions that describe his/her own leadership style and if they had any difficulty or ambiguity the researcher helped them to get the needed data. Each worker was given half an hour time for the completing the questionnaire.

Another thing is that majority of the workers are English dummies and hence, the questionnaire involved in this study was translated in to the Telugu language so that the workers could record their responses. In this manner data was collected from the workers over a month.

\subsection{Reliability and Validity of the Questionnaire}

Reliability and validity are the two important aspects to be considered in evaluating or formulating a questionnaire. These are the criteria used to assess whether the research provides good measures.

The Sage Publication's leadership questionnaire is also a standardized tool and it has been tested for reliability and validity in a number of settings, as stated in the official website of the sage publications. The reliability of the instrument has also been proven on many occasions through test-retest, internal consistency methods and alternative methods. It is valid and reliable and has been used extensively worldwide. It has proven to be a strong predictor of leadership styles across a broad range of employees. Hence it has been concluded that the chosen questionnaire was reliable and valid for use in the present research.

\subsection{Data Collection}

Once the filled-in questionnaires were all collected from the workers, the researcher coded the data as mentioned in the scoring keys given along with the questionnaire. The scores were entered into Microsoft Excel 
spreadsheet and later on into the Statistical Product and Service Solutions (SPSS) for analysis. The cross tabulations and relevant tests were done on the SPSS, for the different cases as needed for the study.

\subsection{Response Rates}

Among the 127 workers (leaders) surveyed only 112 completed the questionnaires in full and all of them have been included in the analyses amounting to a response rate of approximately $88 \%$.

\section{Ethical Considerations}

Bless and Higson Smith (2000), state the main rules of data collection as: a) voluntary participation b) the right to privacy c) Freedom and d) Anonymity e) Confidentiality. All these ethical rules have been met in this research study. The data collected for this research didn't involve any confidential information to great degree. So luckily the researcher managed to collect the data from the workers of the firm with no difficulty. In order not to waste the valuable time of the workers, and not to disrupt the work in the firm, as advised by the managers of the firm, the researcher visited the workers during the lunch breaks and collected the data.

\section{Hypotheses, Tests, Results}

The hypotheses proposed for this study are all null hypotheses only and these will follow now along with the relevant tests and interpretations. The task of the researcher is to accept or reject the null hypothesis after the relevant tests and tabulations.

\section{Hypothesis One}

H1 - There is no significant difference in the number of employees with their inherent leadership styles.

Number of employees -vs- Leadership Styles Cross tabulation
\begin{tabular}{|r|c|c|c|c|}
\hline & \multicolumn{3}{|c|}{ Leadership styles } & \multirow{2}{*}{$\begin{array}{c}\text { Total No., } \\
\text { of emp loyees }\end{array}$} \\
\cline { 2 - 4 } & Autocratic & democratic & $\begin{array}{c}\text { Laissez- } \\
\text { faire }\end{array}$ & 112 \\
\hline $\begin{array}{r}\text { Number of } \\
\text { employees }\end{array}$ & 12 & 70 & 30 & \\
\hline
\end{tabular}

The table presented above reveals that among the sample studied, employees with the democratic leadership traits are more (70) compared to the other two. The Laissez-faire leadership traits occupy the second place with a count of 30 employees and the autocratic leadership style occupies the third position with 12 employees.

From this we can conclude that, there is significant variance in the leadership styles exhibited by the employees of the firm, most of them favoring the democratic leadership style. Hence, we can reject the null hypothesis and as assumed before the democratic leadership has been proved to be the leadership style exhibited by the majority of the employees, compared to the other two styles.

\section{Hypothesis Two}

H2 - There is no significant difference between Male and Female employees in terms of Leadership styles.

Gender - vs - Leadership Styles Cross tabulation

\begin{tabular}{|l|c|c|c|c|}
\hline \multirow{2}{*}{ Gender } & \multicolumn{3}{|c|}{ Leadership styles } & \multirow{2}{*}{} \\
\cline { 2 - 4 } & Autocratic & Democratic & $\begin{array}{c}\text { Laissez- } \\
\text { faire }\end{array}$ & Tota1 \\
\hline Male & 10 & 64 & 29 & 103 \\
\hline Female & 2 & 6 & 1 & 9 \\
\hline Total & 12 & 70 & 30 & 112 \\
\hline
\end{tabular}




\begin{tabular}{|c|c|c|c|c|c|c|}
\multicolumn{1}{|c|}{ Group Statistics t - test } \\
\cline { 2 - 5 } & Gender & $\mathrm{N}$ & Mean & $\begin{array}{c}\text { Std. } \\
\text { Deviation }\end{array}$ & t-value & $\begin{array}{c}\text { Level of } \\
\text { significant }\end{array}$ \\
\hline $\begin{array}{c}\text { Leadership } \\
\text { Styles }\end{array}$ & Male & 103 & 57.7767 & 6.21815 & \multirow{2}{*}{2.269} & .05 \\
\cline { 2 - 7 } & Female & 9 & 53.0000 & 6.04152 & & \\
\hline
\end{tabular}

From the above table it is found that the $\boldsymbol{t}-\boldsymbol{v a l u e}$ is significant at 0.05 levels and it shows that there is significant difference between the male and female respondents in terms of exhibiting their leadership styles.

Hence the above null hypothesis stating that - 'there is no significant difference between the male and female respondents in terms of Leadership styles' - is rejected. Therefore the study proved that there is some significant difference in leadership styles exhibited by the male and female workers in the firm.

\section{Hypothesis Three}

\section{H3 - There is no significant variance among respondent age groups in terms of Leadership styles}

Age - vs - Leadership Styles Cross tabulation
\begin{tabular}{|c|c|c|c|c|}
\hline \multirow{2}{*}{ Age } & \multicolumn{3}{|c|}{ Leadership styles } & \multirow{2}{*}{} \\
\cline { 2 - 5 } & Autocratic & Democratic & $\begin{array}{c}\text { Laissez- } \\
\text { faire }\end{array}$ & Tota1 \\
\hline Up to 25 yrs & 0 & 2 & 0 & 2 \\
\hline 26 to 35 yrs & 5 & 14 & 2 & 21 \\
\hline 36 to 45 yrs & 3 & 22 & 10 & 35 \\
\hline 46 and above & 4 & 32 & 18 & 54 \\
\hline Total & 12 & 70 & 30 & 112 \\
\hline
\end{tabular}

The above cross tabulation depicts the relationship between the variable Age and Leadership styles and it shows interesting results. It states that up to 35 - years of age, the employees are displaying more the autocratic leadership style. After that they are exhibiting more of the democratic leadership style up to 45 years of age. After that they incline towards the laissez-faire leadership style. It is interesting to see that the democratic leadership is the dominant one among the three leadership styles under study and the older people exhibit different leadership behaviors compared to the youngsters.

The above cross tabulation reveals that, there is significant variance among employee age groups in terms of leadership styles. From this we can reject the null hypothesis stating - "there is no significant variance among the different age groups of employees in terms of leadership styles" - and the study proves age has its influence on the leadership styles of the workers.

\section{Findings of the Study}

Based on the cross tabulations and statistical tests, the findings of the study are: a) the study has concluded that all the leadership styles are not equally present in the employees, inherently. The democratic leadership style is more dominant among the employees, the Laissez-faire comes next and the autocratic style of leadership is exhibited by least number of employees. b) Some significant difference exists between male and female workers in terms of exhibiting their leadership styles in the sample studied. The female employees are more autocratic to some extent than the male employees as per the study. d) The study shows that the age too affects the leadership styles of the employees. e) The individuals start with more of the autocratic leadership style and then move towards democratic in their middle ages and then at the later stages turn towards the laissezfaire leadership style.

\section{Discussions}

The findings of this study are in excellent agreement with the other findings already established in the leadership literature and it is good to see there are no contradicting findings from this study. All the findings are congruent with the established facts of leadership. a) This study has concluded that all the inherent leadership styles are not equally present in the employees, investigated. The democratic leadership style is more dominant among the employees, the autocratic style comes next and the Laissez-faire leadership is exhibited by least 
number of employees. This finding is in agreement with the findings (2010) of Gholamreza Taleghani, Davood Salmani and Ali Taatian, based on their study on the leadership styles survey in different cultures. The study of Javed Sawati, Saeed Anwar, Iqbal Majoka (2013) is also in agreement with the finding of this study. b) The study indicates that, there is some significant difference between the male and female employees in terms of exhibiting their leadership styles in the sample studied. The female employees are more autocratic to some extent than the male employees as per the study. Emotionally, there is some significant different between the male and female employees, according to psychology (Goleman, 1995) and the leadership theories have proved that emotional intelligence has its impact on the leadership style. So, it is natural that the male and female employees exhibit different leadership styles, in conforming to the established principles of psychology and leadership theories (Winter and others., 2001). c) The study says that the age too affects the leadership styles of the employees. The individuals start with more of the autocratic leadership style and then move towards democratic in their middle ages and then at the later stages turn towards the laissez-faire leadership style. This is in agreement with the established principles of educational psychology. With growing knowledge, individuals will adjust to their surrounding and are capable of understanding others better. With increasing age, knowingly or unknowingly individuals acquire more knowledge and naturally people tend to be more flexible and less assertive. So, they will exhibit lesser authority on their fellow beings. Another reason is that with growing age physically individuals start to depend on others for some type of help and this too might affect their psychology and this will affect their leadership styles. This finding is in agreement with the work (2009) of Per Erik Solem on 'Age Changes in Subjective Work Ability' and with the work of Belal et al., (2010) apart from many others.

\section{Limitations of the Study}

Some of the limitations of this research study are: a) not all the workers in the firm were studied b) only one select firm was examined c) geographically the study is confined to a particular town d) only the three and not all leadership styles were examined e) as in any research study, finance is a constraint and hence, the easily available leadership questionnaire was used in this study and it might have some inherent deficiencies. Due to these reasons the findings may not be the general results.

\section{Conclusions}

The two variables chosen for this study - Age and Gender - indeed have their respective influence on the leadership styles of the workers. The study indicates that the democratic leadership style is dominant among the workers and with increasing age, the workers tend to exhibit lesser authority and the female employees are more autocratic in nature.

\section{References}

[1] Adeyemi, T. O (2004). Educational administration: An Introduction. Lagos: Atlantic Associated Publishers. p.71-86.

[2] Adeyemi, T.O. (2007): Research Methods and Theses Writing in Educational Studies. Lagos: New Haven Publishers.

[3] Adeyemi, T.O., Bolarinwa,R. (2013). Principals' Leadership Styles and Student Academic Performance in Secondary Schools in Ekiti State, Nigeria. International Journal of Academic Research in Progressive Education and Development, 2(1), 187-198.

[4] Ahiazu, A. I. (1989). The "Theory A" system of work organization for the modern African workplace. International Studies of Management and Organization, 19(1), 6-27.

[5] Andrew J. DuBrin (2009): Leadership: New York, USA: Houghton Mifflin Company.

[6] Babcock. L (2008), "What happens when women don't ask?" Negotiation, Vol. 11, No. 96, pp. 1-4.

[7] Bass, B.M. (1990). Handbook of leadership: Theory, research, \& managerial applications, Third edition. New York: Free Press.

[8] Beckman. D and Menkhoff. L (2008), "Will women be women? Analyzing the gender difference among financial experts," Kyklos, Vol. 61, No. 3, pp. 364-384.

[9] Belal A. Kaifi, Bahaudin G. Mujtaba (2010), "Transformational Leadership of Afghans and Americans: A Study of Culture, Age and Gender”, Journal of Service Science \& Management, DOAJ, DOI: doi:10.4236/jssm.2010.31019

[10] Bless, C. and Higson Smith, C. (2000), Fundamentals of Social Research Methods, 3ed, Lusaka: Juta Education (Pty) Ltd.

[11] Cagle,S.G. (1988). Fiedler's Contingency Theory of Leadership Effectiveness and Appointment of a Committee Chairperson. Dissertation Abstracts International, Volume: 50-07, Section: B, page: 2842

[12] Eagly, A. H., Karau, S. J., \& Makhijani, M. G. (1995). Gender and the effectiveness of leaders: A meta-analysis. Psychological Bulletin, 117,125-145.

[13] Goleman. D. (1995): Emotional Intelligence. New York: Bantam.

[14] Kearney. E (2008), "Age differences between leader and followers as a moderator of the relationship between transformational leadership and team performance,” Journal of Occupational \& Organizational Psychology, Vol. 81, No. 4, pp. 803-811.

[15] Kelman, H. (1958). Compliance, identification, and internalization: Three processes of attitude change. Journal of Conflict Resolution, vol.1, 51-60.

[16] Lantz. P (2008), "Gender and leadership in healthcare administration: 21 st century progress and challenges," Journal of Healthcare Management, Vol. 53, No. 5, pp. 291-301.

[17] Li, L., Tse, E., C.Y., \& Xie, L. (2007). Hotel general manager profile in China: A case of Guangdong Province. International Journal of Contemporary Hospitality Management, 19(4), 263-274.

[18] Mirani, Z.D., Narejo, M.A., \& Kumbhar, M.I. (2003).Essential leadership competencies needed in agricultural occupations as identified by agricultural leaders in district Hyderabad, Sindh. Pakistan Journal of Applied Sciences, 3(1), 30-35.

[19] Ogunsanwo, O. A. (2000). Modern Principles and Techniques of Management Ibadan: External Studies Program, Department of Educational Management University of Ibadan. 
[20] Ojode, L. A., Walumbwa, O., \& Kuchinke, P. (1999, April). Developing human capital for the evolving work environment: Transactional and trans-formational leadership within an instructional setting. Paper presented at the meeting of the Midwest Academy of Management, Lincoln, NE.

[21] Payden, B. L. (1997). The relationship between perceived leadership behaviors and job satisfaction based on age, gender, and education level variables. Dissertation Abstracts International: Section A: Humanities \& Social Sciences, 57(7-A), 3127.

[22] Per Erik Solem (2009), "Age Changes in Subjective Work Ability", International Journal of Ageing and Later Life, DOAJ, DOI:10.3384/ijal.1652-8670.083243

[23] Rasor, C. E. (1995). An analysis of the relationship between personality preference traits of executive level and mid-level law enforcement/corrections leaders and exemplary leadership practices. Dissertation Abstracts International: Section A: Humanities \& Social Sciences, 56(4-A), 1436.

[24] www.sagepub.com/northouseintro2e

[25] Sheikh, A.G. (2001). "Leadership Styles as Viewed by Secondary School Head Teachers of Lahore City", Institute of Leadership and Management, Lahore, Affiliated with Hamdard University, Karachi Pakistan. Master thesis in education Studies of Management and Organization, 19(1), 6-27.

[26] Taylor, T. R. (1998). Factors influencing the effectiveness of cross-function-al work teams in a research and development organization. Dissertation Abstracts International: Section B: The Sciences \& Engineering, 58(10-B), 5685.

[27] Thomas, B. B. (1996). The relationship of leadership style to teacher leadership preferences. Dissertation Abstracts International: Section A: Humanities \& Social Sciences, 57(1-A), 0064.

[28] Thompson, M. D. (2000). Gender, leadership orientation, and effectiveness: Testing the theoretical models of Bolman, Deal, and Quinn. Sex Roles, 42,969-993.

[29] Titus Oshagbemi, (2004) "Age influences on the leadership styles and behavior of managers", Employee Relations, Vol. 26 Iss: 1, pp.14 - 29 [ DOI: 10.1108/01425450410506878]

[30] Van Engen, M. L., and Willemsen, T. M. (2004). Sex and leadership styles: A meta-analysis of research published in the 1990s. Psychological Reports, 94,3-18.

[31] Van Vugt. M (2006), "Evolutionary origins of leadership and followership," Personality\& Social Psychology Review, Vol. 10, No. 4, pp. 354-371.

[32] Winter. J, Neal. J, and Waner. K (2001), "How male, female, and mixed-gender groups regard interaction and leadership differences in the business communication course," Business Communication Quarterly, Vol. 64, No. 3, pp. 43-58.

[33] Yukl. G. (2002). Leadership in Organizations, 5 Ed. New Jersey: Prentice Hall. 